Anal ysi s of Heart Rate in Devel opi ng Bi $r d$ Enbryos : Effects of Devel opment al Mode and Nass

\begin{tabular}{|c|c|}
\hline $\begin{array}{l}\text { 弚の他 (別言語等) } \\
\text { のタイトル }\end{array}$ & $\begin{array}{l}\text { 成長する鳥類胚における心拍数解析：成長モード } \\
\text { と卵質量の効果 }\end{array}$ \\
\hline 著者 & AR Anos, TAZAWA H r oshi \\
\hline $\begin{array}{l}\text { j our nal or } \\
\text { publ i cat i on titl e }\end{array}$ & Menmi rs of the Mr or an Inst i tute of Technol ogy \\
\hline vol une & 49 \\
\hline page $r$ ange & 61- 71 \\
\hline year & 1999-11- 30 \\
\hline URL & ht t p: //hdl . handl e. net /10258/154 \\
\hline
\end{tabular}




\title{
Analysis of Heart Rate in Developing Bird Embryos: Effects of Developmental Mode and Mass
}

\author{
Amos $\mathrm{AR}^{*}$ and Hiroshi TAZAWA**
}

(Accepted 31 August 1999)

Bird embryos may be regarded as developing in their thermo-noutral zone, at rest, and stay in the egg for a fixed period of time until hatching. It is therefore interesting to investigate if they follow the same "rule" set for adult homeotherms, which states that, within a taxonomically or functionally defined categoty such as mammals or birds, the number of heart beats throughout the life span $\left(s_{L}\right)$ is more or less constant. This rule stems from the allometrio relationships between heart rate (HR) and body mass $\left(m_{B}\right)$ and between $s_{\text {: and }} m_{B}$.

As a step towards understanding the general allometric nature of avian embryonic physiology we analyzed the HR values of avian embryos in relation to their incubation span $\left(s_{f}\right)$.

Data from 30 species were selected from the scientific literature for the analyses. Values obtained from invasive methods which were judged to grossly alter natural incubation conditions, or from undefined of unmatched temperature conditions were not used. These include most values obtained below the first 308 of the incubation. Also, data obtained after internal pipping were discarded since hatching activity influences them. Values for $s_{I}$ and egg mass $\left(m_{\varepsilon}\right)$ as representative of embryonic mass were also collected.

Embryonic HR was normalized to70.1-80\% $s_{1}$. At 20.1-30z $s_{1}$ it was only $85 \%$ of the value at $70.1-80 \% s_{1}$ and increased to a plateau at about 50.1-608 $s_{1}$. It was almost constant among species between 50.1 $608 s_{I}$ and pre-internal pipping (PIP) time and thus, the mean HR valuo between 50.1-608 $s_{I}$ and 90.1-100\% excluding pipped eggs (MHR) was taken as a representative value for each given species. The MER(bpm) and the corresponding $s_{i}$ (d) values for the 30 species, scaled with $m_{g}$ ( $g$ ) as follows: MRR $=371 . \mathrm{I} \cdot m_{\varepsilon}^{-0.112}$ and: $s_{y}=12.29 \cdot m_{\varepsilon}^{+a_{2} 209}$. Both powers were significantly different from $a$. The product of MHR and $s_{z}$ (NHR $\cdot s_{1}$ ), representing the total number of heartbeats throughout the incubation, scaled with $m_{E}$ for the entire data set as follows; MHR $s_{I}=6.565$. $10^{+6} \cdot m_{\varepsilon}{ }^{+0.096}$, where the +0.096 power is significantly different from 0 . Values for MHR $\cdot s_{1}$ from ambryos of altricial birds tended to concentrate at the low $m_{\varepsilon}$ end of the plot while those of the precocial ones tended towards the high end. Separate enalyses showed that the $m_{\Sigma}$ power for the combined altrieial and semi-altricial species (ASA), and the combined precocial and semi precocial species (PSP), of log MHR. $s_{z}$ against $\log m_{x}$ regressions, were both insignificantly different from 0 . Thus, means of MHR $\cdot s$, far ASA and PSP were calculated. The mean ASA value of $7.27 \cdot 10^{\text {t6 }}$ hedtheats for $M H R \cdot s_{I}$, was significantly different from the mean PSP value of $10.93 \cdot 10^{+6}$. The difference of $3.66 \cdot 10^{+5}(33.58)$ heart beats can be attributed to either the more advanced stage of the PSP hatchlings at hatch, to the larger $m_{\mathrm{s}}$ values of these hatchlings, to the difference on water fraction of the hatchlings or ali. The result of a linear regression of MHR $s_{i}$ in $d^{-1}$ 
units) against the rate of $s_{1}$ completion (the inverse of incubation span, $f_{I} ; d^{-1}$ ) was: MHR $\cdot 10^{-6}=0.205+3.940 \cdot f_{I}$. Thus, the fastor is the average rate of development accomplished per day (shorter incubation) the higher is dally heart rate. Data tended to cluster such that large eggs, mostiy of the PSP type with relatively low MHR, complete 2 to 48 of their incubation per day, while small, ASA type eggs with relatively high MHR, complete 6 to $8 \%$ of their incubation time per day.

We conclude that, at this stage of knowledge, the data is insufficient to resolve whather the different modes of hatch stage alone can explain differences in the total number of heortbeats throughout embryonic life among all bird species, or egg mass and water content differences contribute variability. This should be investigated on a larger sample of species in more depth.

Keywords: Allometry, Altriciality, Avian Embryo, Avian egg, Development, Feart rato, Incubation, Precociality

\section{RATIONALE}

\section{1 Homeotherms}

The oxygen consumption rate per unit $m_{g}$ in the thermo-neutral zone $\left(\mathrm{sp} \mathrm{Vo}_{2}\right.$, an indicator of mass-specific resting metabolic rate), scales in both mammals and birds in the same way and is roughly in proportional to the -0.25 power of their $m_{B}$. For adult passerines (all altricial): $\mathrm{spVO} \mathrm{O}_{2}=129 \cdot \mathrm{m}_{\mathrm{a}}^{-0.276}$, and for non-passerine (mostly precocial): $\operatorname{spVO}_{2}=78 \cdot m_{\mathrm{B}}^{-0.277}$ (189) where $m_{\mathrm{a}}$ is in $\mathrm{kg}$ and $\mathrm{spVO}_{2}$ is in $\mathrm{kcal} \cdot(\mathrm{d} \cdot \mathrm{g})^{-1}$. Heart mass, blood volume and stroke volume $\left(Q_{s}\right)$ are isometrically related to $\mathrm{m}^{\{6,7,9,12,19\}}$. Cardiac output $(Q)$ is well matched with $\mathrm{sp} \mathrm{VO}_{2}$, at least for resting metabolic rate conditions. Since $Q=\mathrm{HR}, Q_{s}, \mathrm{HR}$ must scale roughly with $m_{\mathrm{m}}^{-0.25}$ (40). In fact, HR of birds in general is: $\mathrm{HR}=178.5 \cdot \mathrm{m}_{\mathrm{n}}^{-0.282}$ where HR is in beats per minute. A similar equation was calculated for adult nonpasserine birds: $\mathrm{HR}=155.8 \cdot \mathrm{m}_{\mathrm{g}}^{-0.23}$ (9), but in a different set of data ${ }^{(6)}$ it was found that: $\mathrm{HR}=175.6 \cdot m_{3}{ }^{-0.209}$, where in all cases $m_{\mathrm{z}}$ is in $\mathrm{kg}$. The similar mass powers reported for $\mathrm{spVO}_{2}$ and $\mathrm{HR}$ indicate that they may be directly correlated at any given $m_{\mathrm{g}}$.

The life spans $\left(s_{1}\right)$ of mammals and birds can be approximated as a function of their $m_{n}^{+0.25}$ although they differ in their proportionality constants. Somewhat lower powers have been reported for free living birds and when not separated to passerines and non-passerines ${ }^{(7,9,10,14,23,24,28,29)}$. The general trend, however, indicates that on the average both mammals and birds survive a fixed amount of heartbeats since: HR. $S_{t}$ $\mathrm{k} \cdot{m_{\mathrm{B}}}^{-0.25} \cdot \mathrm{k}^{\prime} \cdot{\mathrm{m}_{\mathrm{a}}}^{+0.2 \mathrm{~s}} \mathrm{~m}$, where $\mathrm{k}$ and $\mathrm{k}^{\prime}$ are

Department of Zoology, Tel Aviv University;

"Department of Electrical and Electronic Engineering the proportionality constants for the relationship between $H R$ and $s_{L}$ to $m_{B}$ respectively, and $\mathrm{K}$ is a constant number of heartbeats. The $\mathrm{K}$ value is a number, which describes a similarity criterion between species ${ }^{(39)}$. The value for adult manmals is $1.47 \cdot 10^{+9}$ heartbeats per life $\operatorname{span}^{(40)}$ and for adult birds it is: $2.32 \cdot 10^{+9}$ heartbeats per life $\operatorname{span}^{(2)}$.

To speculate, it seems that life time in homeotherms lasts a given quantity of actions or events occurring in a mass unit. Life would have been longer if the rate at which these actions occur was slower and vice versa. However, the pace and/or life span are not arbitrarily set - they are strongly correlated with the animal's body mass.

\subsection{Avian embryos}

Bird embryos nay be regarded as developing in their thermo-neutral zone, at rest, and stay in the egg for a given period of time in preparation for hatching. It is therefore interesting to investigate if they too follow the same allometric "rules" set for adult homeotherms and if similarity criteria may emerge within a taxonomically or a functionally defined category such as in bird embryos. In particular, it is of interest to elucidate if a similarity criterion, such as the $k$ above, emerges from the allometric relationships between $H R$ and fresh egg mass $\left(m_{\mathrm{z}} ;\right.$ representing embryonic mass) and between $s_{x}$ and $m_{F}$.

\section{3 oxygen consumption rate.}

The shape of the curve describing sp $\mathrm{Vo}_{2}$ of a bird embryo with incubation time $\left(s_{I}\right)$ is characteristic for each species. However, if $s_{I}$ is normalized to 100 and $\mathrm{spVO}_{2}$ is either normalized to 100 at PIP time ( $\mathrm{Ca} 908$ of $s_{\mathrm{r}}$ ) or to mid-"plateau" value (a period during incubation starting 
shortly before PIP time and characterized by a sudden change in the slope of $\mathrm{spVO}_{2}$ vis a vis time), a pattern emerges which seems to be similar in all species and varies mainly in the duration of the above mentioned "plateau" stage ${ }^{(18,29,50,51)}$. Embryos of altricial species (and/or species possessing small eggs) tend to have short or even almost no plateau (lasting of up to 12.4 웅 $s_{Y}$ ) while precocials (and/or species possessing large eggs) tend to have a well pronounced plateau (lasting up to $16.9 \% s_{I}$ $\left.{ }^{(30)}\right)$. The value of PIP $\mathrm{spVO}_{2}$ was found to be allometrically related to $m_{\mathrm{E}}$ in the form of:

sp Vo $=22.2 \cdot m_{E}^{-0.228}$ (after ${ }^{34}$ ) and:

$\mathrm{spVO}=28.9 \cdot m_{\mathrm{E}}{ }^{-0.286}$ (after ${ }^{18}$ ), where spVo is in $m l[S T P D] \cdot(g \cdot d)^{-1}$ and $m_{E}$ is in $g$.

The power values in the equations above fluctuate (depending on the sample) below and above those shown for the relation of $\mathrm{SpVO}_{2}$ at $\mathrm{BMR}$ and $m_{B}$ of adult birds ( -0.25$)$. Note that bird embryos may be regarded as developing in their "thermoneutral zone" "at rest" and in a quasisteady state. This is because analysis shows ${ }^{(17)}$ that tissue maintenance accounts for about 70-80\% of the total energy used up during development, even without taking into account the metabolism assigned to the extra embryonic membranes. However different models give estimates for maintenance cost, which are somewhat lower (12).

1.4 Incubation duration and oxygen consumption

From literature data it is possible to show an inverse relationship between PIP $\operatorname{sp} \mathrm{VO}_{2}$ and $s_{I}$ such that the product of the two averages ca $273 \mathrm{ml}[\mathrm{STPD}] \cdot(\mathrm{d} \cdot \mathrm{g})^{-1}$ of $\mathrm{O}_{2}$ for all bird embryos ${ }^{(3)}$. During other equivalent fractions of incubation, hence in equivalent embryonic developmental stages, the normalized $\mathrm{spVO}$ values ( $\left.\mathrm{VO}_{2} / \mathrm{PIP} \mathrm{sp} \mathrm{VO}_{2}\right)$ are also similar among species. (At least within altricial and precocial embryos). Thus, the areas under the curves, describing $\mathrm{sp} \mathrm{Vo}_{2}$ as a function of incubation time, are proportional, and it is justifiable to integrate the total. amount of $\mathrm{O}_{2}$ consumed per gram fresh egg mass during the entire incubation period $\left(\sum \mathrm{sp} \mathrm{Vo} \dot{\mathrm{V}}_{2}=\right.$ totVo $_{2}$; ml [STPD]. $\mathrm{g}^{-1}$ ) for comparing different species. The totvo $\mathrm{O}_{2}$ was indirectly estimated to be 90 $\mathrm{ml}[S T P D] \cdot \mathrm{g}^{-1}$ of egg mass regardless of $m_{\mathrm{z}}$ and $s_{I}{ }^{(1)}$. An average value of $102 \mathrm{ml}[\mathrm{STPD}] \cdot \mathrm{g}^{-1}$ was calculated for 34 species (19). It appears that totvo (which, when transformed into energy units per gram egg, describes the total energetic cost of converting $m_{E}$ unit into an equivalent unit of chick mass) varies in a narrow range. Among altricial species it is ca 0.3 to $1.1 \mathrm{~kJ} \cdot \mathrm{g}^{-1}$, and among precocial species - ca 0.4 to $2.1 \quad \mathrm{~kJ} \cdot \mathrm{g}^{-1}{ }^{(50)}$. From calculated values given in ${ }^{(1)}$ it can be concluded that the energetic cost of producing precocial hatchling (per gram of fresh egg mass) is ca 25\% higher than that of altricial hatchling. This difference between altricials and precocials disappears when tot $\mathrm{VO}_{2}$ is expressed as a fraction of the energy utilized and transformed per gram egg $(\mathrm{kJ} / \mathrm{kJ})$ to form the (yolk-sac free) hatchling, because it disregards the higher watex concentration in altricial hatchlings. It amounts at hatch, in all maturity forms, to an average of $35 \%$ of all energy utilized and transformed ${ }^{(4)}$. This fractional value seems to represent an embryonic similarity ariterion as defined above. As shown in the development above, it must be constant if $s_{I}$ scales with $m_{\mathrm{E}}$ the same way as $s_{\mathrm{I}}$ scales with $m_{E}$. If this is the case, as suggested before ${ }^{(29)}$, then a constant number of metabolic events, associated with totvo $\mathrm{O}_{2}$, signify the embryonic development. One of these amounts could be the total number of heartbeats during the embryonic life, which represents the total number of oxygen pulses.

From studies, which show that growth time and time to sexual maturity in mammals are a fixed fraction of $s_{t^{(10,37)}}$ it can be inferred that $s_{I}$ is proportional to $s_{I}$ of birds. More over, fledging time and time to first reproduction are also directly proportional to $s_{1}$ in birds ${ }^{(10)}$. Time spans of various variables in birds have been summarized $^{(29)}$. In 5 stidies, $m_{E}$ power values for $s_{1}$ ranged from to.16 to $+0.24^{(29)}$. The study concluded that the costs of embryogeny, ontogeny and maturity all scale with mass in the same way and are constants per unit mass, i.e. the durations of these stages are in a fixed proportion to each other ${ }^{(30)}$. It is interesting to note that a difference was found between altricial and precocial birds in $s_{1}$. In the same sample, the $m_{B}$ powers for $s_{ \pm}{ }^{1}$ were +0.29 and +0.22 for altricial and precocial species respectively(59). Thus, a search for a $k$ value of avian embryos seems to be justified.

\subsection{Caraiac functions}

The proportions of $m_{\mathrm{a}}$ of the avian embryo at different developmental stages to both initial $m_{p}$ and hatchling mass are rather fixed ${ }^{16,35)}$. We have analyzed chick embryo data ${ }^{(36)}$ and found that the fractional heart mass of the embryo stays constant throughout incubation $(0.56 \%)$. Fractional heart mass of adult birds is about 1 (10) $^{(10)}$. Hence, $Q_{s}$ at any embryonic stage must be also directly correlated with embryonic mass and thus with $m_{z}$. 


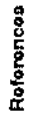

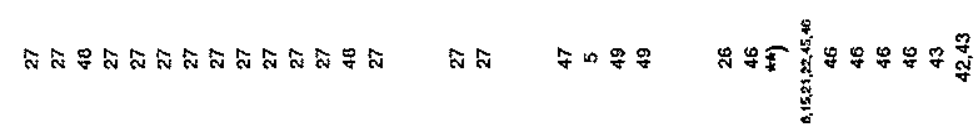

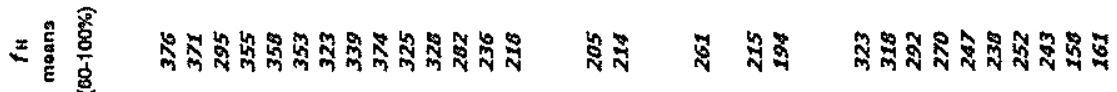

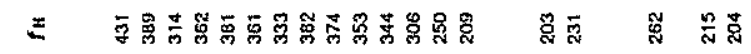

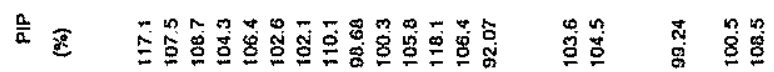

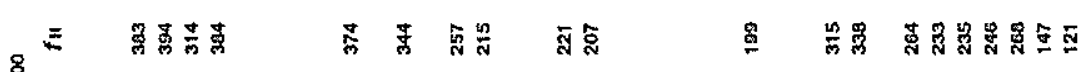

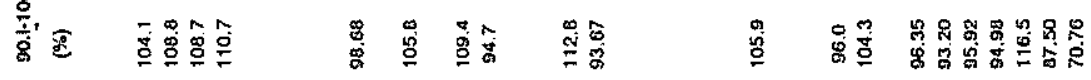

$\stackrel{\mathrm{g}}{\mathrm{g}}$



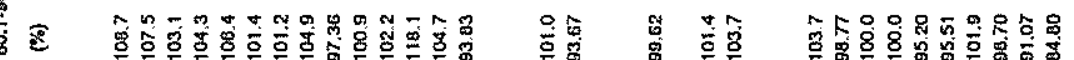

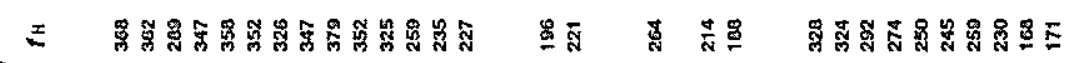

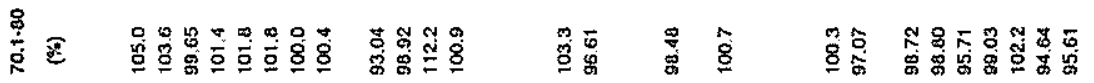



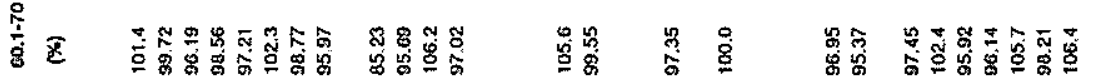

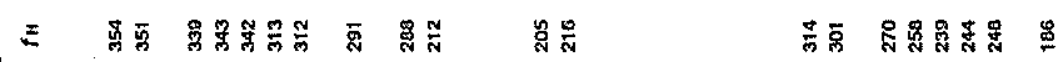

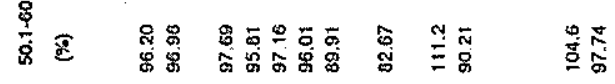

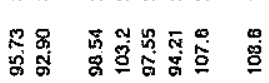

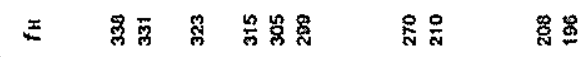

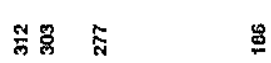

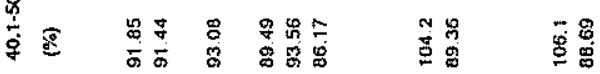

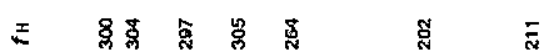

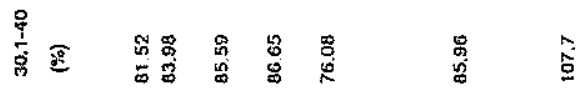

$\pm$

(8)

俤

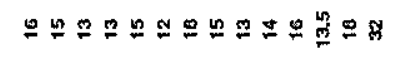

สูก

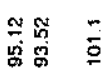

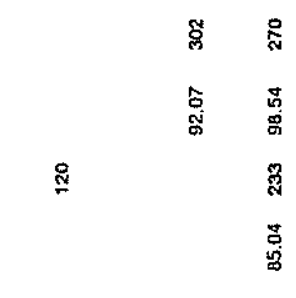

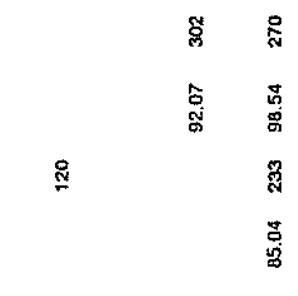

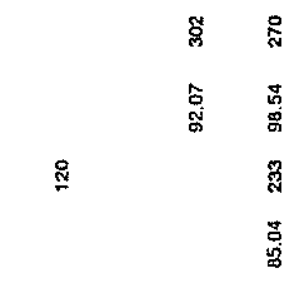

要

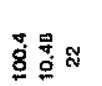

$\underline{8} \underset{8}{8} \div$

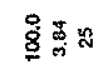

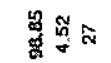

草是

(1)

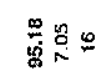

政

预昆=

동ํㅎㅇ

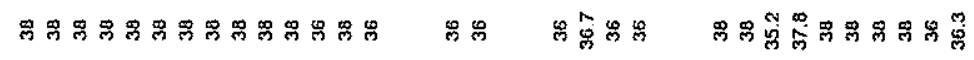



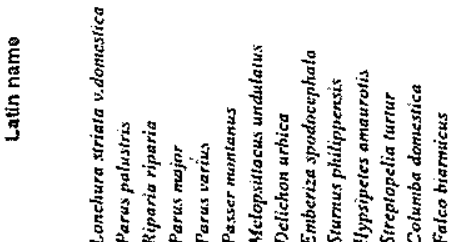

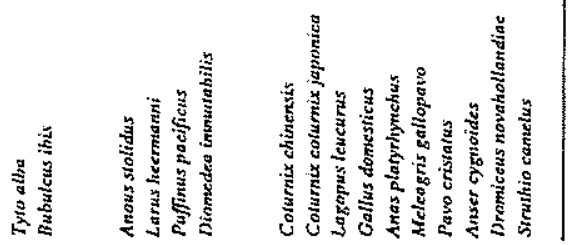

害的
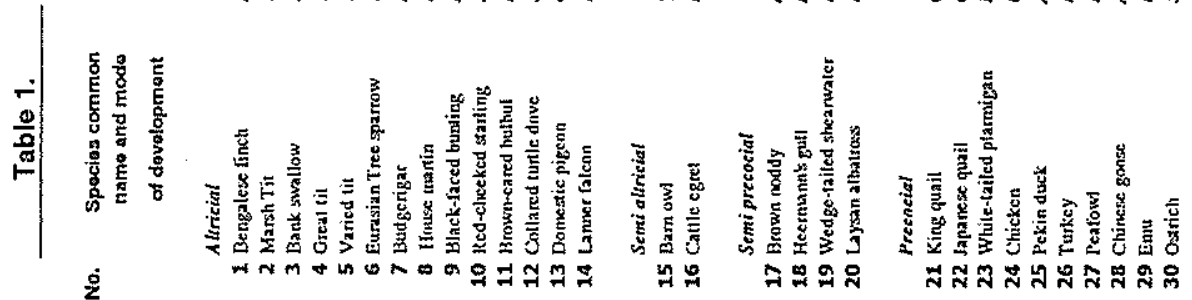
On this basis we hypothesize that $Q$, and thus $H R$, would be proportional to the same $m_{E}$ power as $s_{I}$ with a negative sign, and that the integrated heart beat number throughout the incubation span wolld yield a $K$ constant which represents a similarity criterion for the total number of heart beats of avian embryos during incubation.

\section{MATERIALS AND METHODS}

Egg masses, incubation durations, incubation temperatures and heart rate data were collected from scientific publications (Table 1). Care was taken to ensure that individual species values of $S_{I}$ and $H R$ correspond to the incubation temperatures given, whether in nature or in the laboratory. Only HR values, which were obtained using methods, which did not alter the physiological state of the embryo, were used. Thus, methods, which involved opening of the eggshell, which may change dramatically the gas pressures over the chorioallantoic membrane, or those incubated at uncontrolled temperature, were eliminated. For this reason we could not use data of embryonic ages below the 20.1 30 percentile of the incubation duration.

The final list of 30 species, which was subjected to our analysis, is given in Table 1. Species were arranged according to their maturity rank at hatching following the conventional classification ${ }^{3}{ }^{3}$, after $\left.{ }^{25}\right)$. Within each group, species were arranged in ascending order of their fresh egg mass.

Conventional statistical methods were employed using STATISTICA/W $5.0^{\langle 41\rangle}$. Model I regression was preferred for the allometrical relations. This model permits direct comparison with most published data. Also, our data is interspecific and the small number of data points did not permit sub-divisions into lower taxonomic levels, and the performance of nested Awova. Regressions were compared using ANCOVA tests and slope comparison tests. The error variance in heart rate was considered much greater then in egg mass, and at any rate, the same egg mass was used for both the analysis of heart rate and incubation span. The standardized major axis method did not fit here because it is reliable at powers close to 1.0 and the non-linear regression analysis is reasonable only at powers below 0.2 .

\section{RESUJTS AND DISCUSSION}

\subsection{Heart rate and egg mass}

From inspection of the data sets that were chosen for the analysis (references in Table 1), it became obvious that, in many species, young embryos have some what lower heart rates than more mature ones by about
$16-208^{(27,42-50)}$. Towards the end of the incubation, some species increased in HR while some decreased, but no consistent pattern was found ${ }^{(27,42-50)}$. In order to try and choose a representative $\mathrm{HR}$ for any given species, all HR values were grouped according to their relative accurrence during the incubation. Thus, values between 20.1 and $30 \%$ of $s_{I}$ (assigned the value $25 \%$ of $s_{z}$ ), 30.1 and 408 (assigned the value $35 \%$ of $s_{y}$ ) etc. were grouped, and when necessary averaged for each species. These HR values are given in Table 1 . They are also given in percent of their respective values of the 75\% $s_{I}$ group. The $758 s_{x}$ percentile group was chosen as a reference of 100 H $\mathrm{HR}$ since it represented, by inspection, a plateau value for embryonic HR (Fig. 1). Since all HR values of the 758 $s_{I}$ group were assigned the value 100 as a reference value, we interpolated the HR of the 65 and $85 \%$ s $s_{\mathrm{I}}$ groups for each species in order to estimate the variability within the 758 group. The group of $95 \%$ includes only values for non-pipped eggs. The PIP values were discarded from analysis since they may represent activity HR.

A Kruskal-Wallis one-way ANOVA by ranks and single factor ANova tests showed that there was no significant difference in percent $H R$ between the 45 and 95 percentiles of incubation. However, since LST and $\chi^{2}$ tests showed that the $458 \quad s_{I}$ group is significantly different from the others, a mean representing the plateau in $\mathrm{HR}$ was taken for every species between 55 and $95 \% s_{1}$. This mean HR (MHR) is given in Table 1. The relationship between $\mathrm{HR}$ and $m_{E}$ of our data set was:

$$
\begin{aligned}
& \mathrm{MHR}=371 . I \cdot m_{E}{ }^{-0.112} ; \\
& \mathrm{SE}=※ 1.116 ; \mathrm{I}^{2}=0.812 ; \Pi=29 .
\end{aligned}
$$

where the symbol $※$ (representing multiplication or division) becomes \pm in the $\mathrm{log}$ form of the equation. Thus \pm logse is the standard error of estimate. The antilog of $2 \cdot \log S E$ is the factor by which a value of MHR, calculated using a given $m_{\Sigma}$, has to be multiplied and divided in order to estimate its $95 \%$ confidence limits. As can be noticed, the $m_{\mathrm{E}}$ power of $-0.112( \pm 0.010 \mathrm{SE})$ is low when compared with the initially expected value of -0.25 .

Previously published work found differences between the altricial and precocial allometry (see above). We speculated that separating the MHR data into maturity groups could yield different powers. Due to the limited number of data values, we subdivided our values into 2 groups - (a) precocial and semi-precocial species (PSP), and (b) altricial and semialtricial (ASA).

Hence, much in the same way, we have calculated, for MHR of the above 2 maturity 
at hatch categories as a function of their $m_{\Sigma}$, the following:

$$
\begin{aligned}
& \operatorname{MHR}(\operatorname{PSP})=439.1 \cdot m_{E}^{-0.140} ; \\
& S E=※ 1.089 ; \quad r^{2}=0.871 ; n=13,
\end{aligned}
$$

and:

$\operatorname{MHR}($ ASA $)=383.7 \cdot m_{E}^{-0.263} ;$ $S E=\circledast 1.093 ; \quad r^{2}=0.838 ; n=16$.

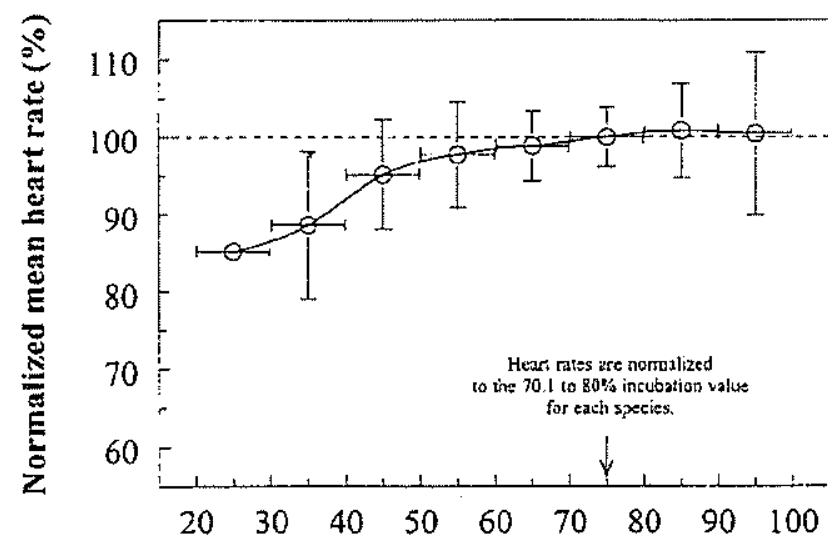

Normalized incubation duration (\%)

Fig. 1. Mean heart rates of avian embryos (Table 1). Species values weire grouped, averaged and presented as percent relative to their intraspecific value at the 758 incubation interval. The normalized heart rate values at different percentiles of incubation were averaged among species. Vertical bars are amongepecies SD. Horizontal bars are the percent incubation zones from which individual species values were grouped and averaged (e.g.70.1 808 is given as $75 \%$ ).

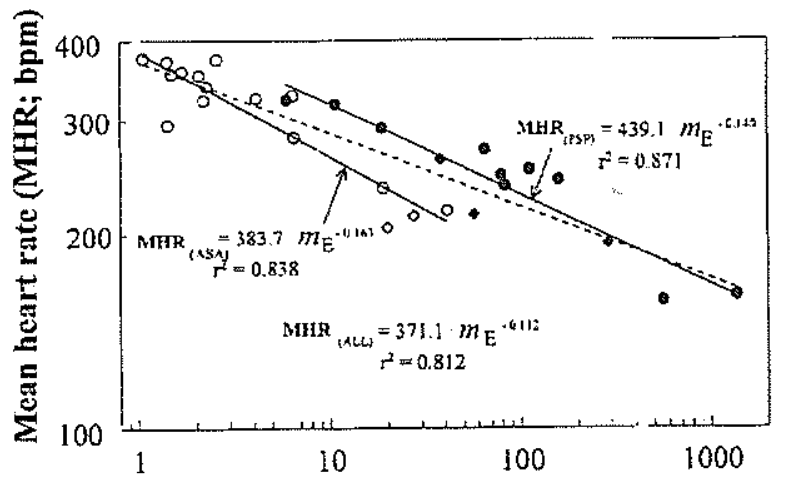

Egg mass $\left(m_{E} ; g\right)$

Fig. 2. Mean heart rate of avian embryos (MHR) as a function of their initial egg mass (EM) presented on log-log soales. Broken line is the regression line for all the data (ALI). Solid lines are for precocial + semiprecocial (PSP) and for altricial + semi-altricial (ASA) embryos. closed circles - precocial eggs; clased diamonds - semi-precocial eggs. Open circles - altficial eggs; open diamonds - semi-altricial eggs.
Both negative powers were higher and significantly different from zero $(p<$ $0.0001)$. There was no difference between the slopes (variance test for slopes; $p=$ 0.3665 ). ANCOVA test gave $F_{1,26}=3.3022$ And $p=0.0807$. This means that when the effect of $m_{\varepsilon}$ is removed there is no difference in MHR between the PSP and the ASA groups. Noticeable increases in $r^{2}$ and decreases in SE were evident, in spite of smaller $n$ values as compared with the overall equation. This indicates that the separation of the MHR data into PSP and ASA groups was justified (Fig, 2).

An equation similar to the one above for PSP has been obtained ${ }^{(46)}$ on 6 precocial species with a lower $m_{\mathrm{z}}$ power value, of 0.106 . The same paper cites unpublished works ( ${ }^{46} ;$ Tullett and Deeming; Rahn and Paganelli) both with low $m_{s}$ powers ($0.107 ; n=6$ and $-0.11 ; n=9$ respectively). This is understandable considering the smaller $n$ values and the scatter of the data. (It has been shown ${ }^{35}$ ) that such regressions tend to underestimate the slopes of linear relations. In our cases: the power functions translate into linear relationships between logMHR and $\operatorname{logm}_{\mathrm{E}}$ where the powers are the slopes of these regressions\}. A power value of -0.12 was found for 3 semi-precocial species ${ }^{(46)}$, and of -0.08 for 2 altricial species ${ }^{(48)}$.

\subsection{Incubation duration and egg mass} The relationship between $S_{I}$ and $m_{z}$ of our data set was:

$$
\begin{aligned}
& s_{z}=12.282 \cdot m_{E}^{+0.207} ; \\
& S E=※ 1.254 ; \mathrm{r}^{2}=0.769 ; n=30,
\end{aligned}
$$

and is similar to that obtained on a much larger data set( ${ }^{(32)}$ :

$$
\begin{aligned}
& \boldsymbol{s}_{Y}=12.03 \cdot \mathrm{m}_{\Xi}^{+0.217} ; \\
& S E=\nVdash 1.237 ; r^{2}=0.860 ; n=475 .
\end{aligned}
$$

However, since a difference was found between the altricial and precocial $s_{4}$ allometry ${ }^{(50)}$ and in order to be able to analyze the relationship between MHR and $s_{I}$, we subdivided again our values into PSP and ASA groups, and obtained:

$$
\begin{aligned}
& S_{I}(\text { PSP })=12.286 \cdot m_{E}^{+0.209} ; \\
& S E=\circledast 1.332 ; \quad r^{2}=0.552 ; n=14,
\end{aligned}
$$

and :

$$
\begin{aligned}
& S_{I}(\text { ASA })=12.532 \cdot m_{\mathfrak{x}}^{+0.187} ; \\
& S E=\circledast 1.194 ; r^{2}=0.632 ; n=16 .
\end{aligned}
$$

There were no significant differences in the slopes $(P=0.7526)$ and intercepts between the equations for the PSP and the ASA groups (Fig. 3). ANCOVA test gave $F_{1,27}$ $=0.0905$ and $p=0,7662$, showing that, 
after removing the egg mass influence, there are no differences in $s_{I}$ between the PSP and the ASA groups.

3.3 Total number of heart beats during incubation

The product MHR. $s_{I}$ of each species in our data set may be regarded as representing an estimate of the total amount of heartbeats of an avian embryo throughout its embryonic development:

$$
\begin{aligned}
& \text { MHR. } s_{1}=6.565 \cdot 10^{+5} \cdot m_{E}^{+0.096} ; \\
& S E=※ 1.248 ; r^{2}=0.434 ; n=29 .
\end{aligned}
$$

Although both the power and the $r^{2}$ values are low, they are significantly different from 0 ( $p<0.0001)$, indicating that there is a residual $m_{E}$ power of $+0.096 \pm 0.021 \mathrm{SEE}$ in the equation and thus MHR. $s_{1}$ is not constant among all embryos in our sample. Furthermore, inspection of the data (Fig. 4) reveals that MHR- $s_{I}$ of small eggs tends to be low,

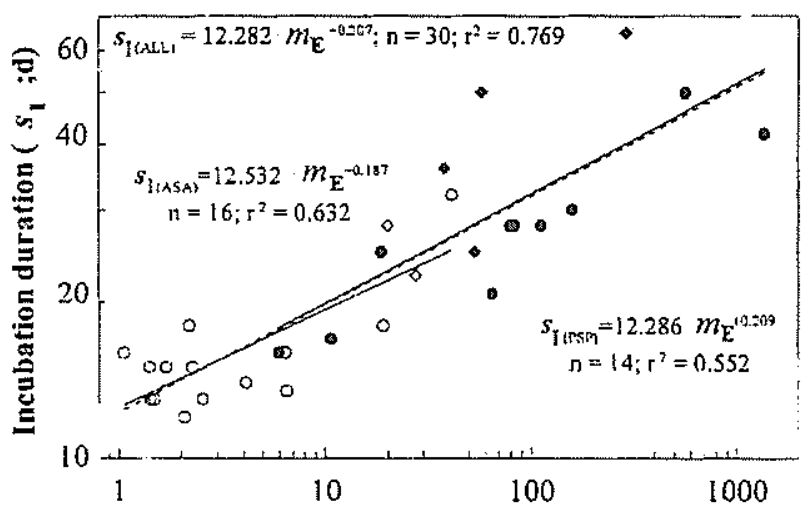

Fresh egg mass $\left(m_{E} ; g\right)$

Fig. 3. The relationship between $\log$ incubation duration (ID) and $\log$ fresh egg mass for the entire date set, for precocial + semiprecocial and altricial + semi-altricial embryos. Abbreviations and symbols are as in Fig. 2 .



Egg mass $\left(m_{E} ; g\right)$

Fig. 4. The total number of heart beats of avian embryos during incubation (HRID) as a function of their initial egg mass, presented on log-log scales. Broken line is the regression line for all the deta. Solid lines are for precocial + semiprecocial and for altricial + semi-altricial embryos. Abbreviations and symbols are as in Fig. 2.

but apparently independent of mass, as compared with relatively large eggs. It was also noted that most ASA eggs of our sample are small (range: $1-41 \mathrm{~g}$ ) in comparison to PSP eggs (range: $6-1362 \mathrm{~g}$ ).

The inspection of the two sets of equations of $s_{I}$ and MHR as a function of $m_{E}$ for the PSP and ASA groups indicated that the hypothesis of a constant MHR- $s_{z}$ should be tested separately for each group according to their maturity. The regressions of MHR. $s_{I}$ on $m_{F}$ yielded (Fig. 5):

MHR. $s_{\mathrm{I}}$ (PSP) $=7.899 \cdot 10^{+6} \cdot \mathrm{m}_{\mathrm{E}}^{+0.067} ;$ $\mathrm{SE}=\nVdash 1.285 ; I^{2}=0.154 ; n=13$,

and:

MHR. $s_{Y}(\mathrm{ASA})=6.924 \cdot 10^{+6} \cdot \mathrm{m}_{\mathrm{E}}^{+0.025} ;$ $\mathrm{SE}=※ 1.187 ; r^{2}=0.031 ; n=16$.

The powers were not significantly different from $0(P=0.185$ and $0.517 ; \mathrm{SEE}= \pm 0.048$ and \pm 0.037 respectively). Since $m_{\mathrm{z}}^{0}=1$ there is no significant effect of $m$ on the MHR. $s_{\mathrm{I}}$ values within each group. Thus, we felt justified to average MHR. $s_{\mathfrak{I}}$ within each group as:

$$
\begin{aligned}
& \text { MHR. } S_{I}(\operatorname{PSP})=10.951 \cdot 10^{+5} ; \\
& S D= \pm 0.309 \cdot 10^{+6} ; n=13,
\end{aligned}
$$

and :

$$
\begin{aligned}
& \text { MER. } S_{1}(\text { ASA })=7.270 \cdot 10^{+6} ; \\
& S D= \pm 0.859 \cdot 10^{+6} ; \Omega=16
\end{aligned}
$$

Both one-tailed and 2-tailed t-tests for unequal variances showed significant differences at the $p=0.001$ level. (Note that the values presented here are probably over estimating the real values because of the relatively low $\mathrm{HR}$ values at the early stages of the development.) The difference between the PSP group and the ASA group in MHR ' $s_{I}$ is $3.682 \cdot 10^{+5}$ heartbeats. The 34 \% higher MHR. $s_{1}$ (FSP) value is in accord with the group's maturity state at hatch and its corresponding higher tot $\mathrm{Vo}_{2}$. It was found that the precocial group is ca $25 \%$ higher in totVo then the altricial one ${ }^{(17,50)}$. Fresh egg content energy stores (per g) of altricial species are smaller in comparison with precocial species by ca 60 to 90 \% $(2,4,11,38,50)$.

Hence, each of the 2 maturity groups can be characterized by a particular similarity criterion - a constant total number of heartbeats throughout incubation. This finding indicates that our initial hypothesis should be modified. It seems to 
hold only within a more homogeneous group, and indicates substantial differences in MHR. $s_{1}$ between the maturity groups tested.

\section{A Egg water content}

While the tot $\mathrm{MO}_{2}$ and energy content values per gram fresh egg mass differ between the maturity groups, the difference tends to disappear when they are recalculated on the basis of dry egg mass ${ }^{[4,50\}}$. This may indicate that egg water content may play a role in differentiating the embryonic pattern of development between PSP and ASA embryos.

So far, egg water content per se is not known to be a factor, which can influence either $s_{I}$ or MHR among species. The differences in $\mathrm{MHR}$. $s_{I}$ between the two groups appear to be linked to the maturity state at hatching which, however, is also linked to both egg (and hatchling) water content and egg (and hatchling) mass ${ }^{(3,15)}$. It would thus be premature or impossible at this stage to conclude that the MHR. $s_{1}$ of bird embryos is dependent on developmental mode only. Water content may play a role as well. We need more data on e.g. Iarge altricial and small precocial bird eggs of different water contents to draw more definite conclusions.

\subsection{Heart rate and developmental rate} If the total amount of heartbeats during incubation as estimated by MHR. $s_{I}$ is fixed within each of the maturity groups irrespective of $m_{\mathrm{E}}$ or $s_{\mathrm{I}}$, then the time interval between 2 heartbeats should be directly proportional to $s_{1}$, and MHR - to an estimate of the rate at which embryonic development proceeds.

We have compared MHR, but this time expressed in per day units (MHR; $d^{-1}$ ), with the developmental rate per day of avian embryos. An estimate of the average developmental rate of avian embryos can be obtained as $\boldsymbol{s}_{I}{ }^{-2}$. Namely, the embryonic development accomplished per day. Since we expected a simple correlation between $f_{H}$ per day and $s_{I}^{-3}$, a linear regression was used. The regression equation for all our data was:

$$
\begin{aligned}
& \mathrm{MHR} \cdot 10^{-6}=0.205+3.940 \cdot s_{\mathrm{I}}^{-1} \\
& \mathrm{SE}= \pm 0.050 ; \mathrm{I}^{-2}=0.729 ; n=29,
\end{aligned}
$$

where MHR is per day. the significant slope indicates that $M H R$ and $s_{I}^{-1}$ are positively correlated (ANOVA test: $F_{1,27}=72.67 ; p<$ 0.0001 ; Fig. 5). Analysis of the individual regressions for the ASA and PSP groups showed that both the slopes and the intercepts are significantly different from 0 but are not significantly different from each other $(\mathrm{p}=0.5852$ and 0.2813 , respectively). Separation into two groups is not justified at this time.

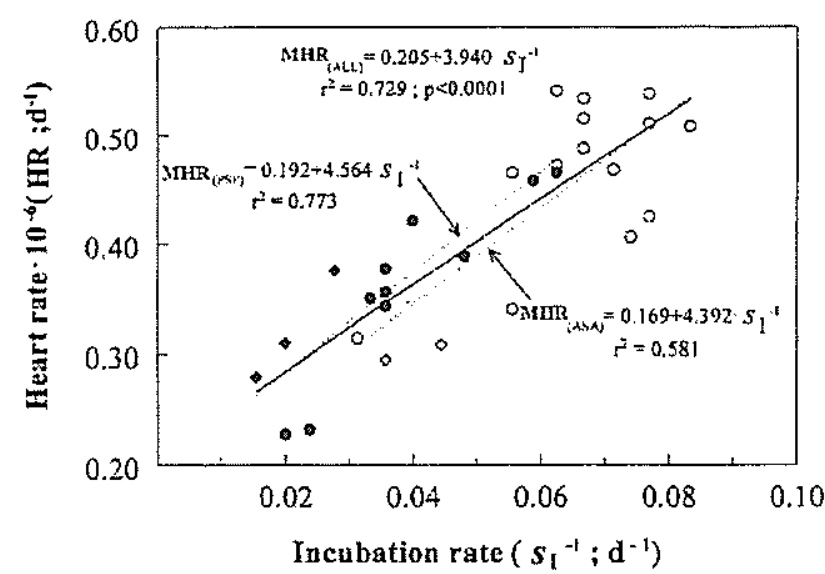

Fig. 5. Mean heart rate of avian embryos expressed in per day units (HRD) plotted vs theix developmental rate, the reciprocal value of their incubation period (IR). Solid line is the regression line for all the data. Dotted lines are for precocial + semiprecocial and for altricial + semi-altricial embryos. Abbreviam tions and symbols are as in Fig. 2 .

Thus, on an inter-specific basis, an increase in the average rate of development among avian embryos (= shortened incubation) is associated with an increase in the number of heartbeats per day.

\section{CONCLUDING REMARKS}

The analysis of log-log relationships between various structural, functional and temporal parameters of avian embryonic development and fresh egg mass, representing the embryo, reveals that they may be regarded as allometrically linked such that some biologically explainable constants or similarity criteria emerge.

In the particular case of the present paper we show that, within functionally linked sub-groups of avian embryos, an estimate for the total number of heartbeats during the entire embryonic development is constant. The magnitude of this constant correlates either with the maturity state at hatch, (which in turn is related to a taxonomic state) or perhaps to egg mass and/or egg water content.

The relatively little data available at this stage makes it difficult to draw final cause and effect conclusions and more information needs to be gathered before final statements can be made.

\section{ACKNOWLEDGEMENT}

We wish to acknowledge with many thanks, the help of Dr. J.T. Pearson and Ms A. Belinsky and $M r$. E. Gefen in various stages of preparing the data for the manuscript. 
This research was sponsored by a JSPS fellowship granted to A. Ar.

\section{REFERENCES}

(1) Ar, A, and Rahn, H., Interdependence of gas conductance, incubation length, and weight of the avian egg. In: J. Piiper (ed,) Respiratory function in birds, adult and embryonic. Springer-verlag, Berlin, (1978), p227-236.

(2) Ar, A. and YomTov, Y., The evolution of parental care in birds. Evolution $32,(1978)$, p655-669.

(3) AI, A. and Rahn, H., water in the avian egg: overall budget of incubation. Amer. zool. 20, (1980), p373-384.

(4) Ar, A., Arieli, B., Belinsky, A. and Yom-Tov, $Y .$, Energy in avian eggs and hatchlings: utilization and transfer. J.exp.Zool.Suppl.1, (1987), p151-164.

(5) Bennett, A.F. and Dawson, W.R., Physiological responses of embryonic Heerman's gulls to temperature. physiol.zool. 52, (1979), p413-421.

(6) Berger, M., Hart, J.S. and Roy, 0.Z., Respiration, oxygen consumption and heart rate in some birds during rest and flight. Z.vergl. Physiologie 66 , (1970), p201-214.

(7) Bishop, C.M., Heart mass and the maximum cardiac output of birds and mammals: Implications for estimating the maximum aerobic power input of flying animals. Philos.Trans.R.soc,Lond. [Biol] $352,(1997), \mathrm{p} 447-456$.

(8) Cain, J.R., Abbott, U.K. and Rogallo, V.L., Heart rate of the developing chick embryo. Proc.Soc.Exp.Biol.Med. 126, (1967), p507-510.

(9) Calder, W.A.III., Respiratory and heart rates of birds at rest. Condor 70 , (1968), p358-365.

(10) Calder, W.A.III., size, function and life history. Harvard University Press, Cambridge, (1984).

(11) Carey, C., Rahn, H. and Parisi, P., Calories, water, lipid and yolk in avian eggs. Condor 83, (1980), p335-343.

(12) Dietz, M.W., Daily energy budgets of avian embryos: The paradox of the plateau phase in egg metabolic rate. Physiol.zool. 71, (1998), pl47-156.

(13) Grubb, B.R., Al. lometric relations of cardiovascular function in birds. Am. J. Physiol. 245, (1983), pH567-H572.

(14) Gunther, B. and de la Barra, I., Physionetry of the mammalian circulatory system. Acta Physiol.Lat.Am. 16, (1966), p32-42.

(15) Haque, M.A., Watanabe, W., Ono, H., Sakamoto, Y. and Tazawa, H., Comparisons between invasive and noninvasive determinations of embryonic heart rate in chickens. Comp.Biochem. Physiol. I08A, (1994), p221-227.
(16) Heinroth, o*, Die Beziehungen zwischen vogelgewicht, Eigewicht, Gelegewicht und Brutdauer. J.ornithol. 70, (1922), p172185.

(17) Hoyt, D.F., A new model of avian embryonic metabolism. J.exp.zool. Suppl.1, (1987), p127-138.

(18) Hoyt, D.F, and Rahn, H., Respiration of avian embryos- a comparative analysis. Respir.Physiol. 39, (1980), p255-264.

(19) Lasiewski, R.C.and Calder, W.A. Jr., A preliminary allometric analysis of respiratory variables in resting birds. Respir.Physiol. 11, (1971), p152-166.

(20) Lasiewski, R.C. and Dawson, W.R., A re-examination of the relation between standard metabolic rate and body weight in birds. Condor 69, (1967), p13-23.

(21) Laughlin, K.F., The effects of restricted gas exchange on embryonic heart rate. In: J. Piiper (ed.) Respiratory function in birds: adult and embryonic.springer-verlag, Berlin, (1978), p298-303.

(22) Laughlin, K.F., Lundy, H. and Tait, J.A., Chick embryo heart rate during the last week of incubation: population studies. Br.Poult.Sci. 17, (1976), p293301 .

(23) Lindstedt, S.L., Body size, physiological time, and longevity of homeothermic animals. Quart.Rev.Biol. $56,(1981), \mathrm{p} 1-16$.

(24) Millar, J.S. and Zammuto, R.M., Life histories of mammals: an analysis of life tables. Ecology 64, (1983), p631635 .

(25) Nice, N.M., Development of behaviour in precocial birds. Linnean society of New York, New York, (1962).

(26) Pearson, J.T., Tsudzuki, M., Nakane, Y., Akiyama, R, and Tazawa, H., Development of heart rate in the precocial king quail Coturnix chinensis. J.Exp.Biol. 201, (1998), p931-941.

(27) Pearson, J.T. and Tazawa, H., Development of cardiac rhythms in altricial avian embryos. Comp. Biochem. Physiol. (in press, also this volume), (1999).

(28) Peters, R.H., The ecological implications of body size. Cambridge University Press, Cambridge, (1983).

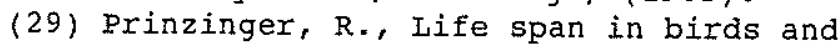
the ageing theory of absolute metabolic scope. Comp.Biochem.Physiol. 105A, (1993), p609-615.

(30) Prinzinger, R., Life stages in birds and aging theories. Interdisciplinary Science Reviews 18, (1993), p35-44.

(31) Prinzinger, R, and Dietz, V., Qualitative course of embryonic $\mathrm{O}_{2}$ consumption in altricial and precocial birds. Resp.Physiol. 100, (1995), p289294.

(32) Rahn, H. and Ar, A., The avian egg: 
incubation time and water loss. Condor 76, (1974), p147-152.

(33) Rahn, H. and AI, A., Gas exchange of the avian egg: time, structure, and function. Amer.2001. 20, (1980), p477-484.

(34) Rahn, H., eaganelli, C.V. and Ar, A., The avian egg: air-cell gas tension, metabolism and incubation time. Respir.physiol, 22, (1974), p297-309.

(35) Riggs, D.S., Guarnieri, J.A. and Addelman, S., Fitting straight lines when both variables are subject to error. Life Sciences 22,(1978), p1305-1360.

(36) Romanoff, A.L., The avian embryo: structural and functional development. The Macmillan Company, New York, (1960).

(37) Schmidt-Nielsen, K., Scaling. Why is animal size so important? Cambridge University Press, Cambridge, (1984).

(38) Sotherland, P.R. and Rahn, H., On the composition of birds'eggs. Condor 89 , (1987), p48-65.

(39) Stahl, W.R., Similarity and dimensional methods in biology. Science $137,(1962), \mathrm{p} 205-212$.

(40) Stahl, W.R., Scaling of respiratory variables in mammals. J.Appl. Physiol. $22,(1967), \mathrm{p} 453-460$.

(4l) STATISTICA/W 5.0. Statsoft. InC, (1985).

(42) Tazawa, H., Ar, A., Gefen, E., Moriya, K. and Pearson, $J+T$, , Effect of incubator humidity on embryonic heart rate in the ostrich. Proc.10th European Poultry Conference, Israel, (1998), p843-847.

(43) Tazawa, H., Ar, A., Gefen, E. and Pearson, J.T., Incubation and heart rate measurement of emu eggs. Proc.10th European Poultry Conference, Israel, (1998), pl19.
(44) Tazawa, H., Ar, A., Pearson, J.T., Moriya, $K$. and Gefen, E., Heart rate in developing ostrich embryos. Brit, Poultry Sci 39, (1998), p161-166.

(45) Tazawa, H., Hashimoto, Y. and Doi, K., Blood pressure and heart rate of the chick embryo (Gallus domesticus) within the egg: responses to autonomic drugs. In: R.B. Hill, K. Kuwasawa, B.R. McMahon, T. Kuramoto (eds.) Phylogenetic models in functional coupling of the cNs and the cardiovascular system. Comp. Physiol. Karger, Basel, (1992), p86-96.

(46) Tazawa, H., Hiraguchi, T., Kuroda, O., Tullett, S.G. and Deening, D.C., Embryonic heart rate during development of domesticated birds. Physiol.zool. 64, (1991), p1002-1022.

(47) Tazawa, H., Kuroda, 0 . and Whittow, G.C., Noninvasive determination of embryonic heart rate during hatching in the brown noddy (Anous stolidus). Auk 108, (1991), p594-601.

(48) Tazawa, H., Watanabe, W. and Burggren, W.W., Embryonic heart rate in altricial. birds, the pigeon (Columbe domestica) and the bank swallow (Riparia riparia). Physiol zool. 67, (1994), p1448-1460.

(49) Tazawa, H. and Whittow, G.C., Embryonic heart rate and oxygen pulse in 2 procellarifiform seabirds, $D i o m e d e a$ immutabilis and Puffinus pacificus. J.Comp.Physiol.B 163, (1994), p642-648.

(50) Vleck, C.M. and Vleck, D., Metabolism and energetics of avian embryos. J.exp.zool. Suppl. 1, (1987), p111-125.

(51) Vleck, C.M., Vleck, D. and Hoyt, D.F., patterns of metabolism and growth in avian embryos. Amer.zool. 20, (1980), p405-416. 


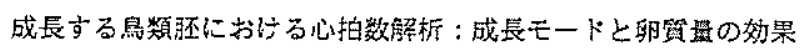

$$
\text { アーアーモズ、田溳 皓"* }
$$

\section{概琶}

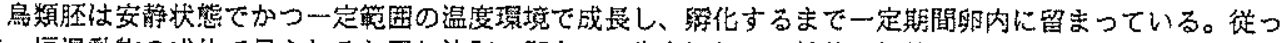

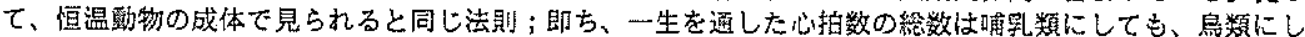
ても多か九少なかれほぼ定であるという法則に従っているかを恰証することは與味のある。この法則は心

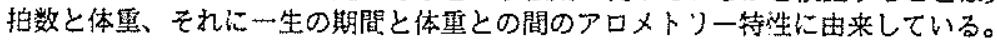

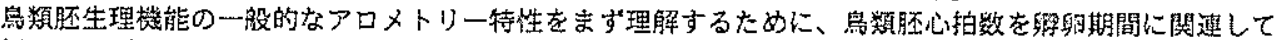

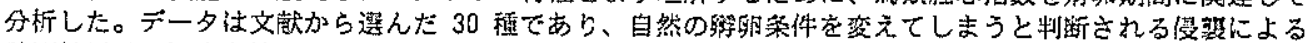

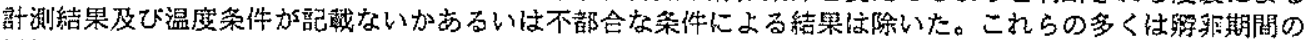

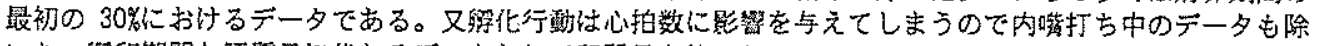

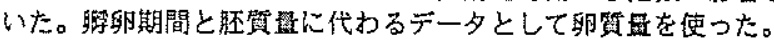

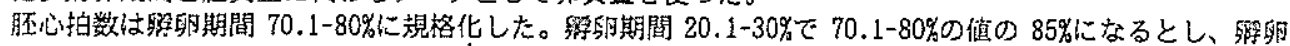

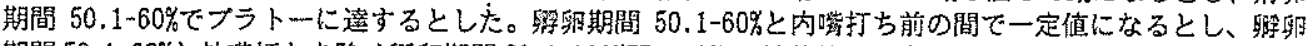

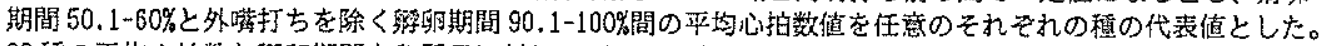

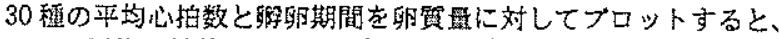

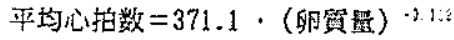

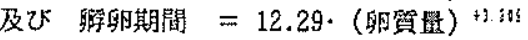

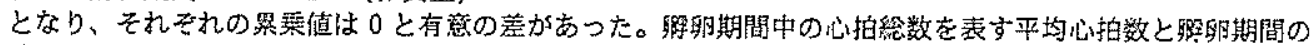

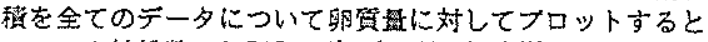

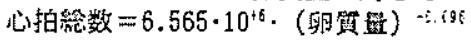

となり、宜焉优+0.096は0と有㮣の差加あった。

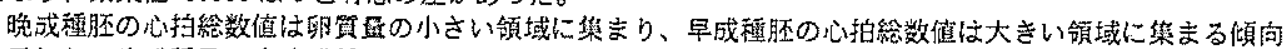

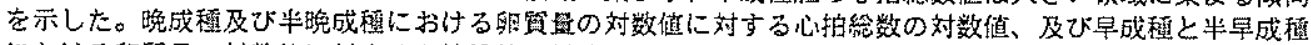

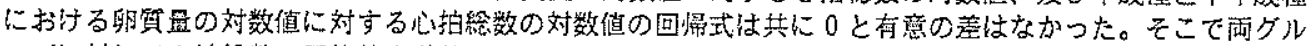

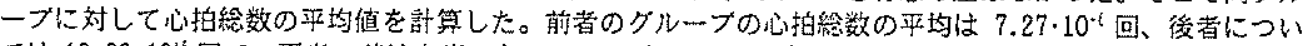



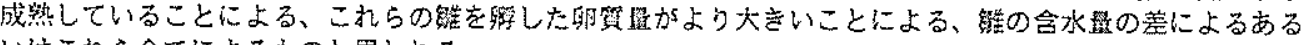
い泣これら全てによるものと思的わる。

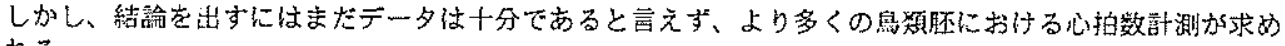
与机。

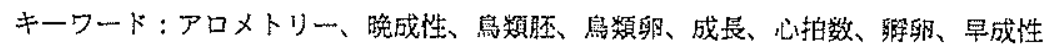

・テルアビブ大学、“麗気電子工学科 